ACCEPTED MANUSCRIPT • OPEN ACCESS

\title{
Protecting rivers by integrating supply-wastewater infrastructure planning and coordinating operational decisions
}

To cite this article before publication: Barnaby Dobson et al 2020 Environ. Res. Lett. in press https://doi.org/10.1088/1748-9326/abb050

\section{Manuscript version: Accepted Manuscript}

Accepted Manuscript is "the version of the article accepted for publication including all changes made as a result of the peer review process, and which may also include the addition to the article by IOP Publishing of a header, an article ID, a cover sheet and/or an 'Accepted Manuscript' watermark, but excluding any other editing, typesetting or other changes made by IOP Publishing and/or its licensors"

This Accepted Manuscript is $\odot 2020$ The Author(s). Published by IOP Publishing Ltd.

As the Version of Record of this article is going to be / has been published on a gold open access basis under a CC BY 3.0 licence, this Accepted Manuscript is available for reuse under a CC BY 3.0 licence immediately.

Everyone is permitted to use all or part of the original content in this article, provided that they adhere to all the terms of the licence https://creativecommons.org/licences/by/3.0

Although reasonable endeavours have been taken to obtain all necessary permissions from third parties to include their copyrighted content within this article, their full citation and copyright line may not be present in this Accepted Manuscript version. Before using any content from this article, please refer to the Version of Record on IOPscience once published for full citation and copyright details, as permissions may be required. All third party content is fully copyright protected and is not published on a gold open access basis under a CC BY licence, unless that is specifically stated in the figure caption in the Version of Record.

View the article online for updates and enhancements. 

infrastructure planning and coordinating operational decisions

Barnaby Dobson ${ }^{1,2}$ and Ana Mijic ${ }^{1}$

1Department of Civil and Environmental Engineering, Imperial College London, London, UK

2Environmental Change Institute, University of Oxford, Oxford, UK

Corresponding author: $\underline{\text { b.dobson@imperial.ac.uk }}$

\section{Key words:}

Integrated water management; Systems analysis; Water system boundaries; Urban water cycle;

Water quality and pollution control; Water resource system modelling; Wastewater modelling;

Word Count (excluding abstract, figures, captions, tables, titles and references); 4411

\section{Abstract}

Placing water quality in rivers at the centre of water infrastructure planning and management is an important objective. In response there has been a range of 'whole system' analyses. Few studies, however, consider both abstraction (water removed from rivers) and discharge (water returned) to inform the future planning of water systems. In this work we present a systems approach to analysing future water planning options where system development prioritises the water quality of the receiving river. We provide a theoretical demonstration by integrating water supply and wastewater infrastructure, and downstream river water quality, on an open-source, stylised, systems model for London, UK, at a citywide scale. We show that models which consider either supply or wastewater separately will underestimate impacts of effluent on the water quality, in some cases by amounts that would require $£ 1$ billion worth of infrastructure equivalent to mitigate. We highlight the utility of the systems approach in evaluating integrated water infrastructure planning using both socio-economic and environmental indicators. Through this approach we find unintended impacts from planning options on downstream river quality; including benefits from water demand management and rainwater harvesting, and costs from wastewater reuse. Finally, we present a novel management planning option between supply and wastewater, which we refer to as Abstraction-Effluent Dilution (AED), that is, to reduce river abstractions during high precipitation events to dilute untreated sewer spills. The AED option is found to provide up to $£ 200$ million worth of equivalent infrastructure in river quality improvements and has minimal impact on the reliability of water supply while requiring only a change in operational decision making. This proof-of-concept study highlights that seeing our water systems differently with this holistic approach could fundamentally change the way we think about future water infrastructure planning so that it works both for people and the environment.

36 around water planning and management (Gleick, 2003; Vörösmarty et al., 2010). Without due 37 consideration to environmental impacts, water infrastructure cannot be described as sustainable 
38 (Loucks, 2000). This desire to put the environment central to planning can be facilitated by a systems modelling approach (Coombes \& Kuczera, 2002; Kasprzyk et al., 2018). When the planning focus

40 changes, specifically to the river quality in this work, the system boundaries may need to be expanded 41 (Vogel et al., 2015). There is a growing literature showing how the expanding of system boundaries changes the behaviour of modelled processes in water systems (Coombes et al., 2016) and even to

43 the extent that would require a system to be managed differently (Dobson et al., 2019b).

44 We look to the urban water system to illustrate this point. It covers rivers, groundwater, wastewater 45 and water supply systems. Each of these systems are typically managed separately yet most of them are operationally connected; for example, water supply abstractions reduce river flows and thus

47 increase the concentration of wastewater effluent discharge in a river. To illustrate this, we show how 48 wastewater and water supply infrastructure interact in catchment management regions across

49 England and Wales in Figure 1. We find that almost half of the catchments have large wastewater 50 plants (serving $>100,000$ people) and water supply abstractions $(>2 \mathrm{Ml} / \mathrm{d})$ interacting by 51 discharging/abstracting from the same rivers (purple, Figure 1E). We see that the remaining 52 catchments have minimal interaction along rivers, with $13 \%$ have wastewater plants and abstractions 53 on different rivers (green, D), 13\% have wastewater plants but no significant abstractions on rivers 54 (orange, C), 16\% have significant abstractions on rivers with no large treatment plants (blue, B) and $5519 \%$ have no significant water infrastructure on rivers (grey, A). 
(B)
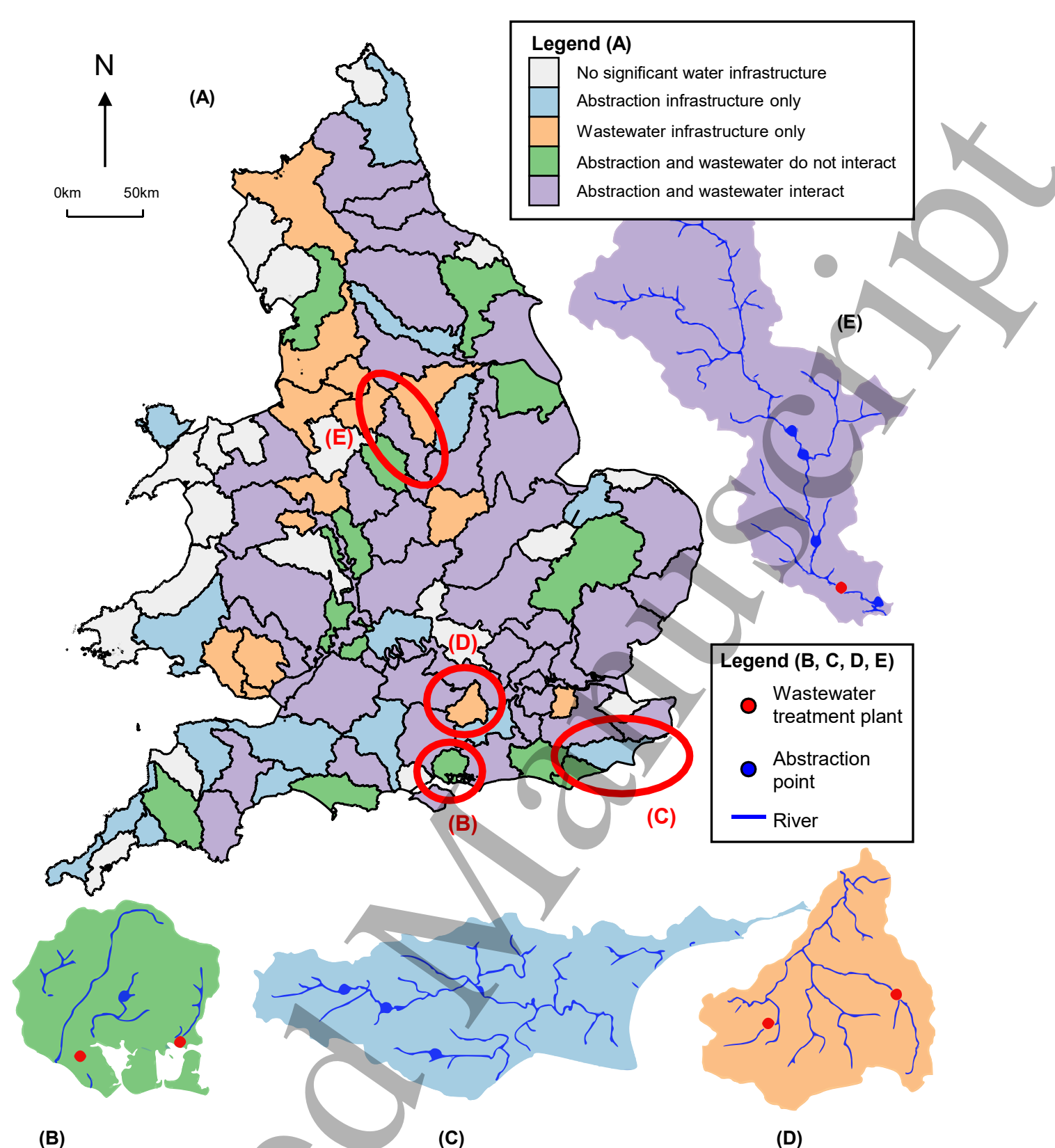

(C)

(D)

Figure 1. (A) A map depicting how different catchments (Environment Agency, 2019a) have different levels of interaction between water supply and wastewater along rivers, indicated by colour. (B-E) Catchments that illustrate different levels of interaction; rivers are shown as blue lines (Ordnance

Survey, 2019), wastewater treatment plants serving $>100,000$ people as red points (European Commission, 2016) and water supply abstractions >2Ml/d as blue points (Environment Agency, 2015).

Despite the interdependency apparent in Figure 1, the UK's supply and wastewater planning processes remain distinctly segregated. In water supply, infrastructure projects are currently evaluated by their impact on continuity of supply, relying on licensed abstraction limits to account for river quality (Cook et al., 2017). In wastewater, there is a focus on the occurrence and severity of both volume and pollutant content of effluent discharges - rather than considering the waters that receive them (Water UK, 2019). Biases in river quality estimation are to be expected for any water 68 infrastructure project if planning remains separate, but the real system is connected. Some 
infrastructure projects, such as wastewater reuse, to be accurately assessed will inherently require conceptualisation over the entire urban water cycle (Behzadian \& Kapelan, 2015).

Models that capture interactions between different water system processes fall broadly under "integrated water management" models (Rahaman \& Varis, 2005; Mitchell, 2006). These types of models are most commonly found as joint sewerage network and urban runoff models (Bach et al. 2014; Salvadore et al., 2015). However, other examples of integrated water management models exist, for example: supply-drinking water quality (Mortazavi-Naeini et al., 2019), household wastesewerage-runoff (Bailey et al., 2019), supply-sewerage-runoff-treatment (Rozos \& Makropoulos, 2013; Behzadian \& Kapelan, 2015; Coombes et al., 2016), and supply-river quality (Paredes-Arquiola et al., 2014). Most integrated modelling applications for planning, thus far, have been focused on the design of new physical components (e.g. installation of wastewater reuse). However, analysis of operational management has been shown to hold great potential in many individual fields of water research, e.g. reservoir optimisation (Dobson et al., 2019a), distribution (Zhao et al., 2016) and wastewater control (Olsson et al., 2014). Therefore, we suggest that considering operational coordination at an urban water system scale would be beneficial and constitute a "joint management" approach. Although we explore one such joint management option in this paper, we envisage that a wide range of alternatives could be revealed with the support of an integrated modelling tool. In this paper, we illustrate a case for a wider systems view of the urban water cycle in water planning and management. We argue that unintended consequences can be incurred by choice of modelled processes resulting in bias for estimating river quality, and that unexpected benefits may be revealed when the system is considered in an integrated fashion. This case is based on three hypotheses. First, we assume that if a city's supply and wastewater systems abstract water and discharge into connected rivers but are modelled separately, then their estimations of river quality will be significantly different than if they had been modelled together. Next, we propose a novel joint management option of reducing water supply abstractions during high precipitation events to dilute sewer spills and reduce the concentration of untreated effluent during spill events to the extent that it could complement infrastructure-based options. Although detailed modelling of the interaction between this joint management option and flood risk is outside the scope of this study, we provide a simple comparison to check the impact. Finally, we argue that water infrastructure planning options will impact state variables across the wider water system revealing co-benefits and trade-offs in integrated water planning. These hypotheses can only be tested in an integrated model that spans the urban water system. Thus, we also present an open-source lumped water management model of a stylised, London-based system.

\section{Methods}

When models aim to represent multiple components of the urban water cycle over large geographical areas, the complexity of the system representations tends to be reduced. This has led to a lumped "directed-graph" approach, pioneered by the Aquacycle software (Mitchell et al., 2001) and with recent implementations such as CityDrain3 (Burger et al., 2016). However, these approaches have been constrained to the wastewater system only. In this work, we build on the lumped directed graph 
approach to facilitate holistic modelling of the urban water cycle. Movement of water is simulated using mass balance equations with simplified representations such as: basic operation rules, proportional mixing of pollutants, seasonal water demand, surface runoff coefficients, and steadystate water treatment. While this approach introduces numerous limitations from a perspective of detailed physically-based modelling (e.g. ignoring biological and chemical influences on water quality, or complex activities that take place to mitigate drought impacts), we believe that the trade-off in process representation is justified in the interest of holistic modelling. We also provide a simplistic validation to ensure the model is sufficient to study the proposed hypotheses in the Experimental Setup section.

\section{CityWat: an open-source water management model of London}

A daily timestep, open-source lumped water management model of a stylised, London-based system (CityWat hereafter) has been developed for this work - see acknowledgements for its Python model code, with equations described in supporting material S1. We note that, although targeted to London, CityWat is modular and can easily be rearranged and generalised to a range of cities. The processes represented in CityWat for this study are depicted in Figure 2A.

(A) Combined Model

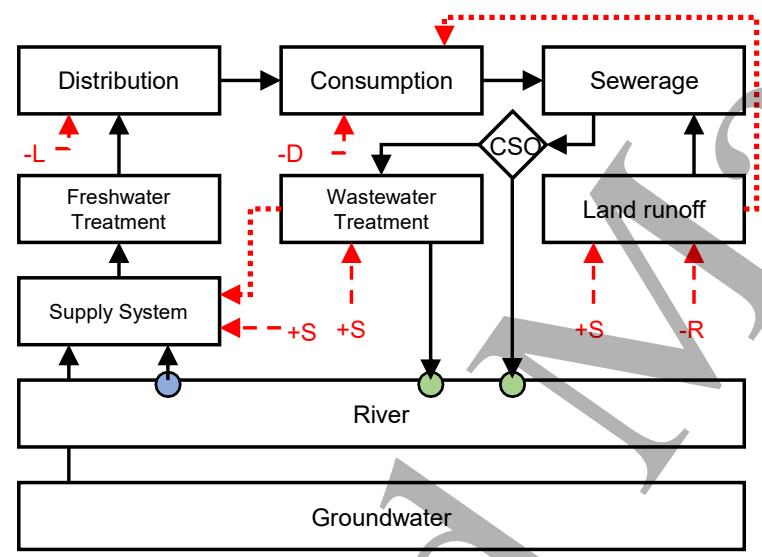

(C) Supply Model

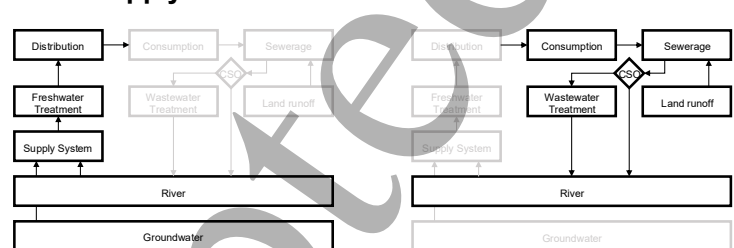

(B) Modelled Domain

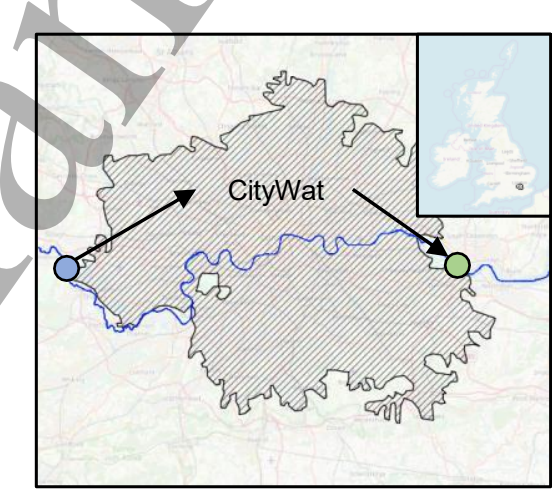

(D) Options Key

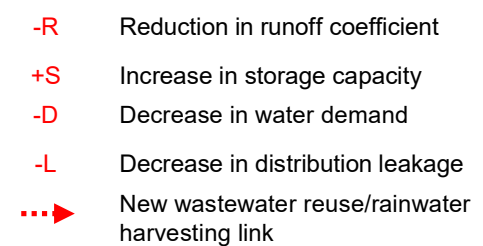

Figure 2. (A, top left) In black is a schematic depicting the processes and data flow represented in CityWat, planning options are highlighted in red. Abstraction and discharges points are indicated in blue and green respectively. CSO stands for "combined sewer overflow" (B, top right) The region represented by our model, with abstraction and discharge locations indicated by circles. $(C$, bottom left) Two framings of the water system, a supply-only model and wastewater-only model. (D, bottom right) The key for the different generic planning options included in our study, which are linked into CityWat illustrated in red in Figure 2A. 
131 Each process in CityWat is represented by a lumped model at city scale, shown in Figure 2B. For

132

133

134

135

136

137

138

139

140

141

142

143

144

145

146

147

148

149

150

151

152

153

154

155

156

157

158

159

160

161

162

163

164

165

166

167

168

169 example, supply reservoirs are aggregated into one London-wide reservoir. This lumping ensures an efficient and easy to understand water management model, and it also enables sharing of parameter information openly without privacy or national security concerns. River flows and groundwater availability are represented by data (detailed in Supplementary Material S2). We note that this is a significant simplification of the real system. There are multiple abstractions and discharge points within the modelled region that CityWat aggregates together as well as upstream processes that model does not represent in detail. Thus, simulation results should be interpreted as a proof-ofconcept rather than assessment or critique of current system operation.

Water system parameters (e.g. capacities of reservoirs or treatment plants) can generally be found openly at city-scale and are described in supporting material S2. Where this was not possible reasonable estimates have been made. S2 indicates the reasoning behind, and supporting sources for these estimates. Input data, i.e. flow and precipitation, have been sourced from the national river flow archive (Centre for Ecology and Hydrology, 2020) and HadUK (Hollis et al., 2019) respectively. London is fortunate in its environmental data records and so the simulation period spans the period between 1903-2018. In the Experimental Setup, we verify how effectively the model simulates historic data.

\section{Impact of water system boundaries on modelled river quality}

The first hypothesis in our case for expanding the model boundaries was that: if a city's supply and wastewater systems abstract and discharge water into connected rivers but are modelled separately, then their estimates of river quality at the downstream boundary will be significantly different than if they had been modelled together. To test this, we treated different models of the system in question each as a plausible representation of the system. Treating a model in this way can be referred to as a 'framing' of the system (Quinn et al., 2017). Thus, we formulated three framings of London's water system. The first is the integrated water system, unchanged from Figure 2A. This combined framing represents the systems view of the urban water cycle. The second is the supply-only portion of the system including processes between the river and point of water consumption by customers, depicted in Figure $2 \mathrm{C}$, left. This is a water supply framing of the water cycle. The third is the wastewater-only portion of the system including processes between the waste production of customers to wastewater treatment work effluent, depicted in Figure 2C, right. This is a wastewater framing of the water cycle.

We hypothesised that downstream river water quality could be a key indicator to assess the performance of the system as a whole. We propose concentration-based metrics formulated from the proportion of downstream river flow. The raw river water, treated effluent and untreated effluent proportions are used to illustrate differences in simulated river quality between framings. Given CityWat's lumped scale, any metric that quantifies the impact of the urban water system on downstream river quality will ultimately be some derivative of these three proportions. As an example of this derivation, we also included phosphorus concentration, which is conceptualised as the phosphorus concentration of raw river water, treated and untreated effluent blended in proportion to their volumetric presence in the river. We chose phosphorus because it is a significant pollutant in the 
170 River Thames and has high concentrations in sewage that are reduced significantly by treatment 171 (Jarvie et al., 2006; Gooddy et al., 2017).

172 To ensure that we consider socio-economic factors as well as environmental, we have also included 173 two metrics for reliability of water supply. These are total supply reservoir volume over time and the 174 level of water use restrictions (e.g. a level 3 restriction allows enforcement of hosepipe bans while a 175 level 4 restriction allows standpipe use). Water use restrictions are based on reservoir levels, described in Mortazavi-Naeini et al. (2019). These metrics do not perfectly capture the complexity of the water resources planning process in the UK (Cook et al., 2017), but we believe serve as an adequate proxy in this proof-of-concept study.

\section{Evaluation of planning options from an environmental perspective}

It became clear when viewing the urban water cycle from a systems perspective, which the combined CityWat framing provides, that there were potential opportunities to improve river quality through a joint management approach. As anticipated in our second hypothesis, we have proposed using water supply abstractions to manage untreated effluent spill events, which we term "Abstraction EffluentDilution" (AED). The working principle behind this option is illustrated in Figure 3 . In the Experimental Setup section, we perform a pilot experiment to design the implementation of this option.

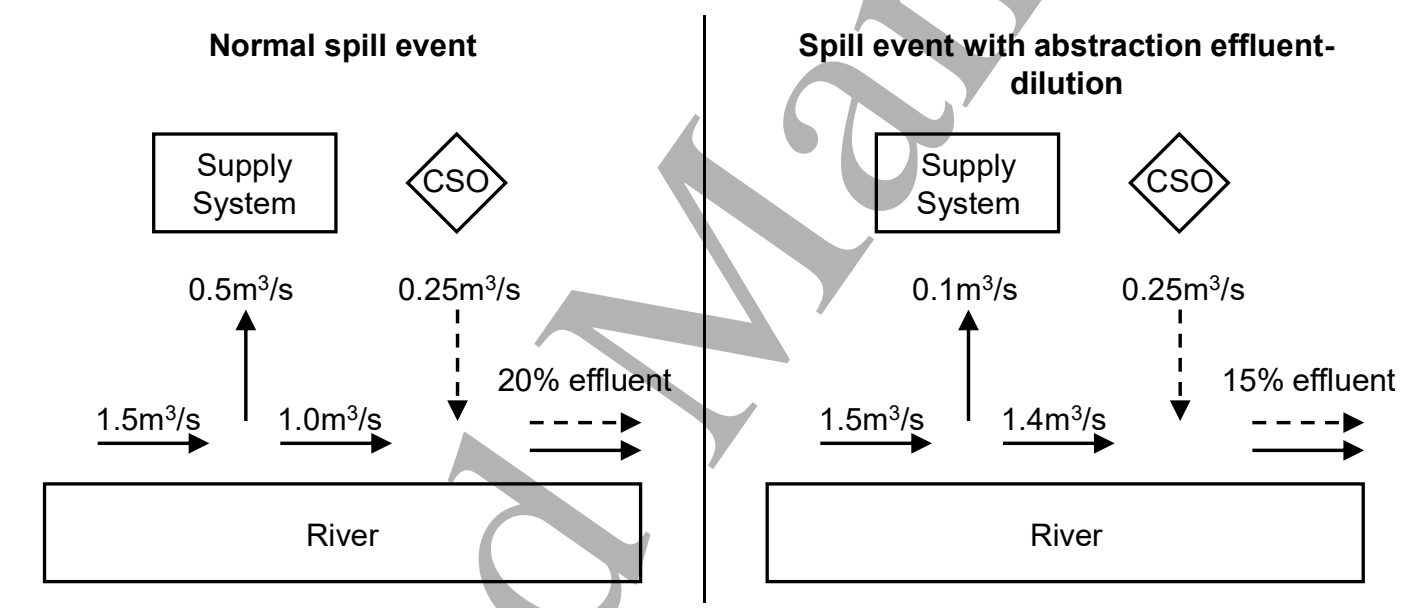

Figure 3. A simplified system schematic that illustrates the working principle of abstraction effluentdilution, with the raw water flows (normal arrows) and untreated spill flows (dashed arrows) represented for a normal spill event (left) and spill event with abstraction effluent-dilution (right). The values shown are for illustrative purpose only and not representative of the case study. CSO stands for "combined sewer overflow".

Besides AED, we also examined conventional water infrastructure options. In the UK, the water supply planning process (termed water resources management planning (Cook et al., 2017)) has been in place since the privatisation of the water industry in 1985, with the feasibility of several project options (e.g. new reservoirs, leakage reduction targets) already assessed. In contrast, the wastewater planning process (termed drainage and wastewater management planning (Water UK, 2019)) is still being developed. Thus, we selected a range of feasible options for supply and commonly proposed options for wastewater planning to test in CityWat alongside AED, which we summarise in Table 1. 


\begin{tabular}{|c|c|c|c|c|}
\hline Sector & Option & Description in model & $\begin{array}{l}\text { Capital } \\
\text { cost }\end{array}$ & Option impact \\
\hline Integrated & $\begin{array}{l}\text { Abstraction } \\
\text { Effluent- } \\
\text { Dilution }\end{array}$ & $\begin{array}{l}\text { Minimise abstractions when } \\
\text { precipitation is high and supply } \\
\text { reservoirs are nearly full }\end{array}$ & Negligible & $\begin{array}{l}\text { Dilutes untreated effluent from } \\
\text { spill events }\end{array}$ \\
\hline Supply & $\begin{array}{l}\text { Wastewater } \\
\text { Reuse }\end{array}$ & $\begin{array}{l}\text { Allows treated effluent to be made } \\
\text { potable and re-directed to the supply } \\
\text { system }\end{array}$ & $\begin{array}{l}£ 2 \mathrm{~m} /(\mathrm{Ml} / \mathrm{d}) \\
\text { (Environment } \\
\text { Agency, } \\
2019 \mathrm{~b})\end{array}$ & $\begin{array}{l}\text { Adds } 150 \mathrm{Ml} / \mathrm{d} \text { in wastewater } \\
\text { reuse capacity }\end{array}$ \\
\hline Supply & $\begin{array}{l}\text { New } \\
\text { reservoir }\end{array}$ & Increase supply reservoir capacity & $\begin{array}{l}\text { £12,500/Ml } \\
\text { (Borgomeo et } \\
\text { al., 2018) }\end{array}$ & $\begin{array}{l}24,000 \mathrm{Ml} \text { increase in reservoir } \\
\text { capacity }\end{array}$ \\
\hline Supply & $\begin{array}{l}\text { Demand } \\
\text { reductions }\end{array}$ & $\begin{array}{l}\text { Reduce per-household water } \\
\text { demand }\end{array}$ & $\begin{array}{l}\text { Negligible (in } \\
\text { comparison to } \\
\text { other options) }\end{array}$ & $\begin{array}{l}10 \% \text { reduction in household } \\
\text { consumption (achievable by } \\
2035 \text {, (Environment Agency, } \\
2019 b) \text { ) }\end{array}$ \\
\hline Supply & $\begin{array}{l}\text { Leakage } \\
\text { reduction }\end{array}$ & $\begin{array}{l}\text { Reduce level of leakage in the } \\
\text { distribution network }\end{array}$ & $\begin{array}{l}£ 1.6 \mathrm{~m} /(\mathrm{Ml} / \mathrm{d}) \\
\text { (NERA, 2019) }\end{array}$ & $\begin{array}{l}190 \mathrm{Ml} / \mathrm{d} \text { reduction in leakage } \\
\text { (about 35\%, achievable by } 2035 \\
\text { (Environment Agency, 2019b)) }\end{array}$ \\
\hline Wastewater & Green roofs & $\begin{array}{l}\text { Reduces equivalent impermeable } \\
\text { area by green roof area multiplied by } \\
50 \% \text { (the assumed runoff reduction) }\end{array}$ & $\begin{array}{l}£ 100 / \mathrm{m}^{2} \\
(\mathrm{AECOM}) \\
2017 \mathrm{a})\end{array}$ & $\begin{array}{l}3 \mathrm{~km}^{2} \text { of green roofs installed, } \\
\text { covering } 2 \% \text { of London's roof } \\
\text { area }\end{array}$ \\
\hline Wastewater & $\begin{array}{l}\text { Rainwater } \\
\text { harvesting }\end{array}$ & $\begin{array}{l}\text { Creates volume that can store } \\
\text { rainwater on roofs and be redirected } \\
\text { to household demand }\end{array}$ & $\begin{array}{l}£ 280 /(400 \mathrm{~L} \\
\text { unit) (AECOM, } \\
2017 \mathrm{a})\end{array}$ & $\begin{array}{l}\text { Units installed on all of London's } \\
\text { roofs, } 700,000 \text { units providing } \\
280 \mathrm{Ml} \text { of storage }\end{array}$ \\
\hline Wastewater & $\begin{array}{l}\text { Stormwater } \\
\text { storage } \\
\text { tanks }\end{array}$ & $\begin{array}{l}\text { Increases storage for water that } \\
\text { reaches treatment works but cannot } \\
\text { be treated that day }\end{array}$ & $\begin{array}{l}\text { £2m/Ml } \\
\text { (AECOM, } \\
2017 \mathrm{~b})\end{array}$ & $\begin{array}{l}\text { Increase temporary stormwater } \\
\text { storage by } 150 \mathrm{Ml} \text {. }\end{array}$ \\
\hline
\end{tabular}

Table 1: A summary of the different options we test in CityWat using a historical demand scenario

(described in Supplemental Material S1), how they are implemented and at what scale. 'Option impact' describes how much of the option could be installed using the costs described in 'Capital cost' with a budget of $£ 300$ million.

In order to compare options from both sectors, we have gathered estimates of unit costs and 204 implement each option with a 'budget' of $£ 300$ million. Some options are constrained by factors other 205 than cost (e.g. demand reductions, whose cost to implement is negligible in comparison with 206 infrastructure projects), thus we provided realistic estimates for these instead. The options we 207 included are illustrated in Figure 2A and 2D.

208 Our third hypothesis was that infrastructure options impact state variables in the systems they exist in, 209 but also those that they interact with, which could have implications for assessing systems level 210 benefits of proposed schemes. Thus, we compared all metrics for all options. 


\section{Experimental Setup}

\section{Verification of the CityWat model}

213 CityWat is a stylised model and primarily illustrative, with parameter values estimated based on 214 openly available data to capture the behaviour of key system processes. We have performed a model 215 verification based on the supply reservoir volume data shared in Mortazavi-Naeini et al. (2019), Figure

2164 . We see that CityWat simulates reservoir volumes broadly in line with other, more complex models 217 of the London's supply system (Nash-Sutcliffe Efficiency $=0.85$ ). The worst model performance is 218 during the 1976 drought. We expect this is due to the lack of emergency supply sources represented 219 in CityWat in contrast to the models it is being compared against. We do not include these emergency 220 supply sources since information about them cannot be made open-source for security reasons and 221 the complexity of decision-making during droughts is increased involving many factors that cannot be 222 modelled in CityWat. Although this will overestimate the absolute occurrence of water use restrictions, 223 all comparisons in this study are relative and thus we expect the impact to be minimal.

224

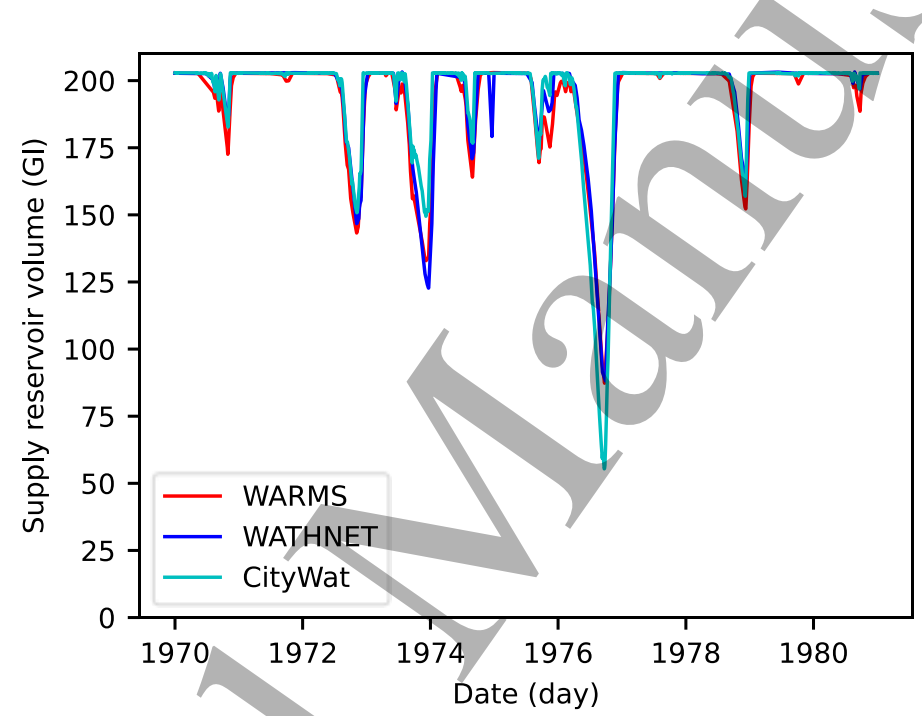

Figure 4. A comparison of active supply reservoir volume for three different daily simulation models of London's water supply. WARMS (red) is the water company model of the system. WATHNET (blue) represents a research water supply model that has been based on WARMS, implemented in the WATHNET supply simulation software (Kuczera, 1992). CityWat (cyan) is the model presented in this study. Gl stands for Gigalitres.

In Figure 5 we compare simulated downstream phosphorus from CityWat with 123 water quality samples at two sampling sites downstream of the modelled region, using data from the WIMS archive (Environment Agency, 2020). The agreement between modelled and sampled phosphorus indicates that CityWat's estimates of treated effluent discharge are reasonable and therefore it is accurately representing wastewater system processes. The two outliers (circled in green), when CityWat simulates much higher levels of phosphorus than the samples, occur during untreated spill events, which the samples do not capture. When these spill events are removed the correlation coefficient with sample site 1 is 0.75 and 0.51 with sample site 2 . 


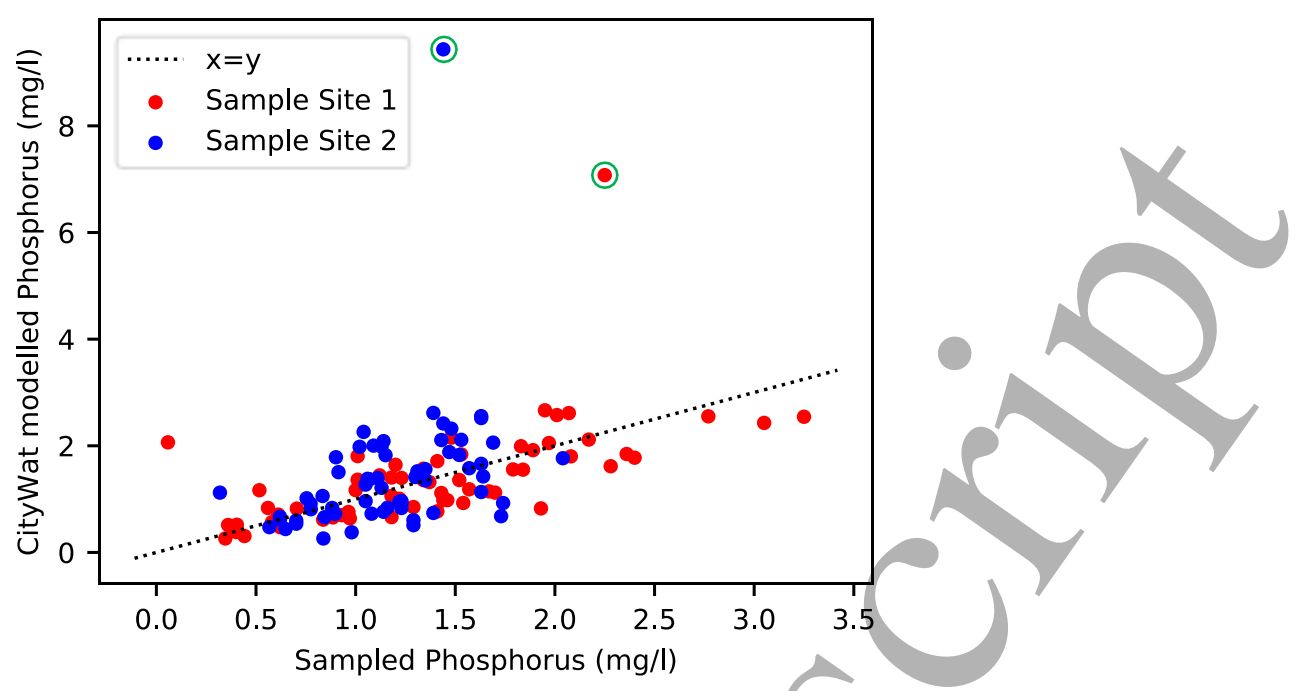

238

239

240

Figure 5. A comparison of phosphorus simulated by CityWat (y-axis) and 123 water quality samples (x-axis) at two different locations (indicated by colour) taken between 2000-2018. Days with modelled combined sewer overflow occurring are circled in green.

The only openly available data on spill events that the authors could identify was that the average annual spill of untreated effluent is between 32-40Mm³/y (Hamilton, 2013). CityWat spills $36 \mathrm{Mm}^{3} / \mathrm{y}^{3}$ on average over the entire simulation period, within the estimated value.

\section{Creating an Abstraction Effluent-Dilution rule}

We now provide a pilot experiment that examines when storm spill events occur to see if they follow any clear patterns to design an AED rule. In Figure 6 we plot the severity of simulated spills (indicated by proportion of river that is untreated effluent) against precipitation data and simulated supply reservoir volume. In Supplementary Material S3, we provide a simple replication of Figure 6 but with river flow to show that $A E D$ is unlikely to significantly interact with flood risk. We note that, were $A E D$ tested in operational conditions, a more complex design would be required than the heuristic we present here to safeguard supply security and test detailed interactions with risks such as flooding. 


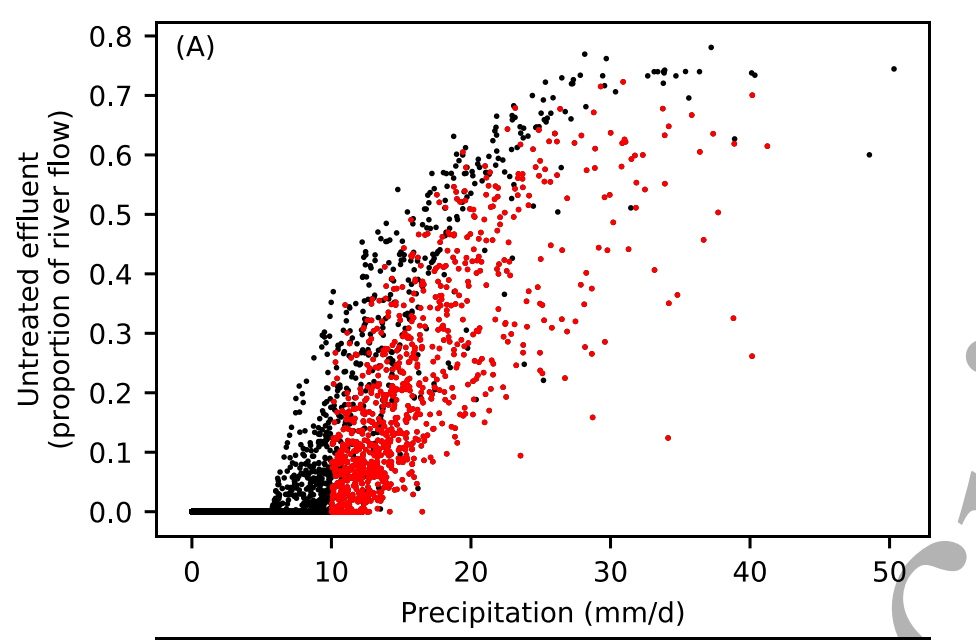

253

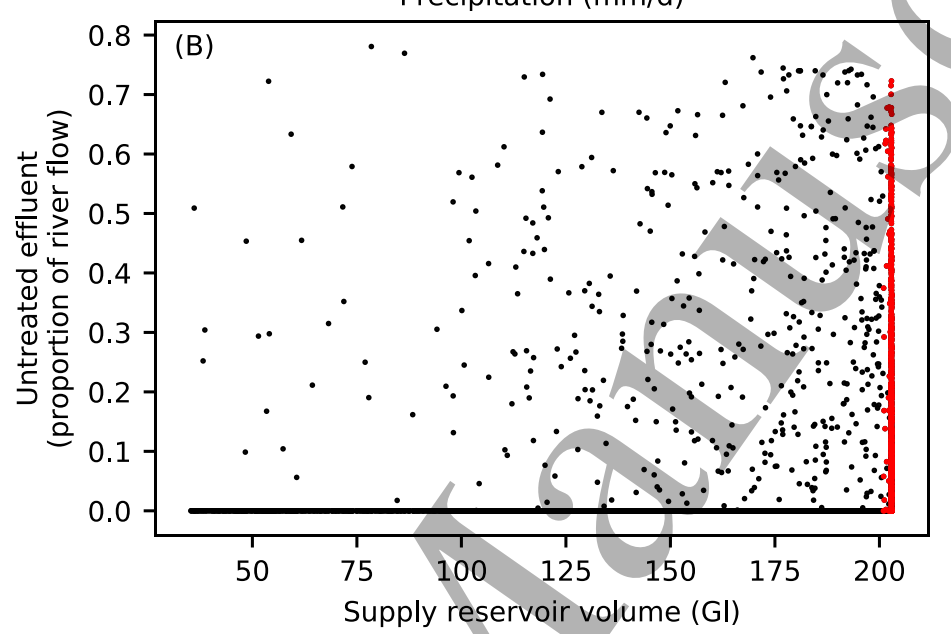

Figure 6. A scatter plot with daily climate data (A) and modelled storage (B), over the period 19032018, on the x-axis with modelled untreated effluent, as simulated by CityWat, on the $y$-axis. Red points are those that occur on days when both precipitation is greater than $10 \mathrm{~mm} / \mathrm{d}$ and supply reservoirs are greater than $99 \%$ full, black points are all remaining days.

Inspecting precipitation, we see that severe spill events typically occur on days when precipitation is $>10 \mathrm{~mm}$ (upper panel, Figure $6,80 \%$ of points that are greater than 0 on the $y$-axis occur with $x$-values greater than 10). We also see that most spill events are occurring when supply reservoirs are nearly full (lower panel, Figure $6,70 \%$ of points that are greater than 0 on the $y$-axis occur with $x$-values greater than 200).

Thus, when the model is run using the 'abstraction effluent-dilution' (AED) option, water supply abstractions on the River Thames are minimized when both reservoirs are $>99 \%$ full and precipitation is $>10 \mathrm{~mm}$. We would not expect this to have a significant impact on reliability of water supply since only $2 \%$ of days (those highlighted in red in Figure 6 ) meet these criteria and if reservoirs are nearly full then under-abstracting is likely to be low risk. Yet abstraction can significantly reduce the flow (up to $5 \mathrm{G} / \mathrm{d}$ ), so we expect that 'leaving it in' could significantly dilute untreated effluent.

9 To test how effective AED is, we examine simulated phosphorus levels. We also test the water supply reliability metrics to check whether the option would put water supply at risk. 
271

272

273

274

275

\section{Results}

\section{Estimates of the impact of model boundaries on water quality}

In Figure 7A-D we plot river quality state variables at the point of downstream discharge estimated by the different framings, showing distinct differences between them. We present a subsection of Figure

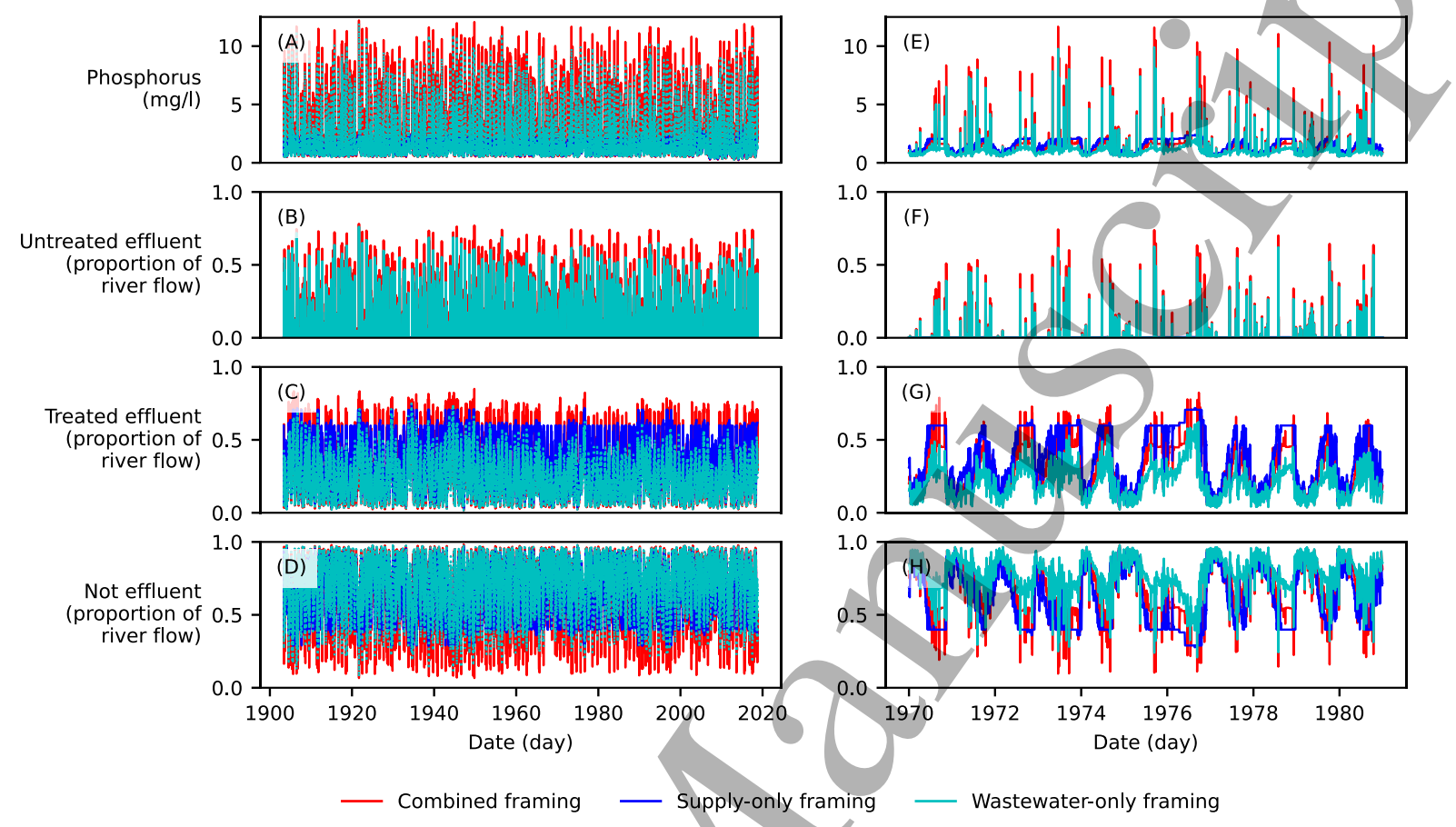

Figure 7. (A-D) Downstream river quality represented by daily effluent and phosphorus concentration

timeseries under the three different model framings (represented by different colours) for the simulation period (1903-2018). (E-H) the same as (A-D) but for a subsection of the simulation period

A significant discrepancy occurs in the supply-only framing. Since it does not represent storm spill events it will not simulate any concentration of untreated effluent (Figure B, no blue) and so underestimates phosphorus concentrations (Figure A, blue never rises above $1.5 \mathrm{mg} / \mathrm{l}$ ).

The wastewater-only framing overestimates downstream river quality in all metrics. By ignoring river abstractions it underestimates treated and untreated effluent concentrations (cyan is lower than red in Figures $\mathrm{B}, \mathrm{C}$ ) and overestimates raw river water concentration (Figure D). This results in underestimating the impact of spill events, although not necessarily their occurrence (red and cyan peaks to line up in Figures B, C). If this framing were used to inform future planning, the equivalent stormwater storage required to reduce untreated effluent spills to these underestimated levels would be 600Ml. Following Table 1, this could exceed £1billion of infrastructure investment.

\section{Abstraction effluent-dilution effectiveness} and with abstraction effluent-dilution (AED). 

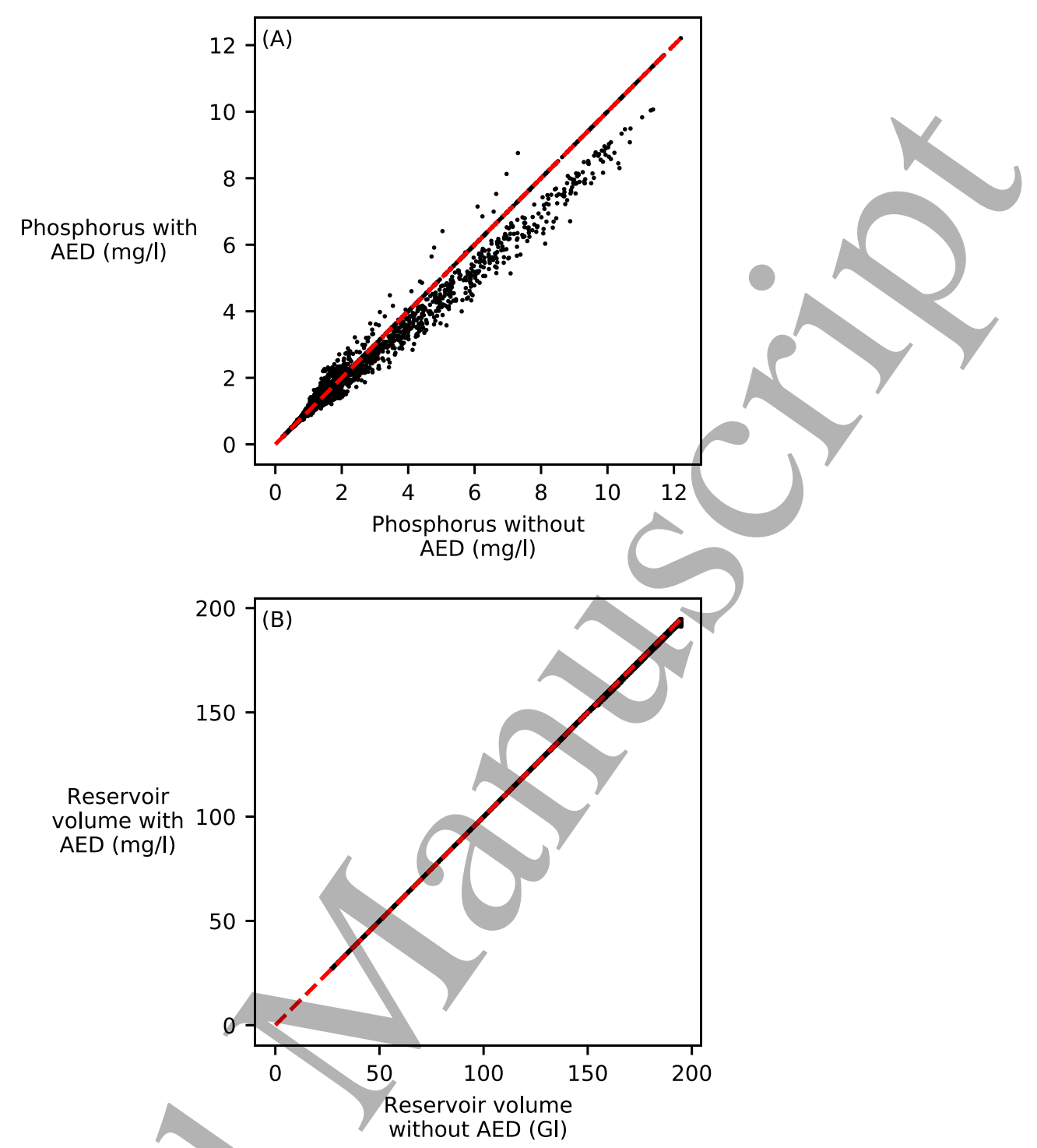

Figure 8. Downstream river quality represented by phosphorus concentration (upper) and water supply reliability represented by reservoir volume (lower) both with ( $y$-axis) and without ( $x$-axis) the abstraction effluent-dilution option (AED) for the simulation period (1903-2018). The red dashed line is $\mathrm{x}=\mathrm{y}$.

We see in the phosphorus levels (upper panel) that AED reduces the severity of spill events (most points are either on or below $x=y$ ). Although AED does not alleviate spills completely, particularly when the reservoirs are at low levels, the volume of stormwater storage that would be required to achieve the same improvement is $200 \mathrm{Ml}$, costing $£ 100$ millions. When inspecting reservoir volumes (lower panel) we also see a small negative impact (points are slightly below $\mathrm{x}=\mathrm{y}$ ). These lower volumes increase the level of restrictions by an additional six days of level one restrictions over the entire simulation period. Since these do not cause actual disruptions, only representing awareness campaigns (Mortazavi-Naeini et al., 2019), we can consider this impact negligible. 
Systems assessment of water management options

308 In Figure 9, we plot how the different options change state variables that indicate system performance 309 averaged over the entire timeseries. A greener colour indicates an improvement (e.g. reduction in 310 water-use restrictions or increase in proportion of downstream river flow that is not effluent), grey 311 indicates no change and pink indicates a worsening (e.g. increase in untreated effluent).

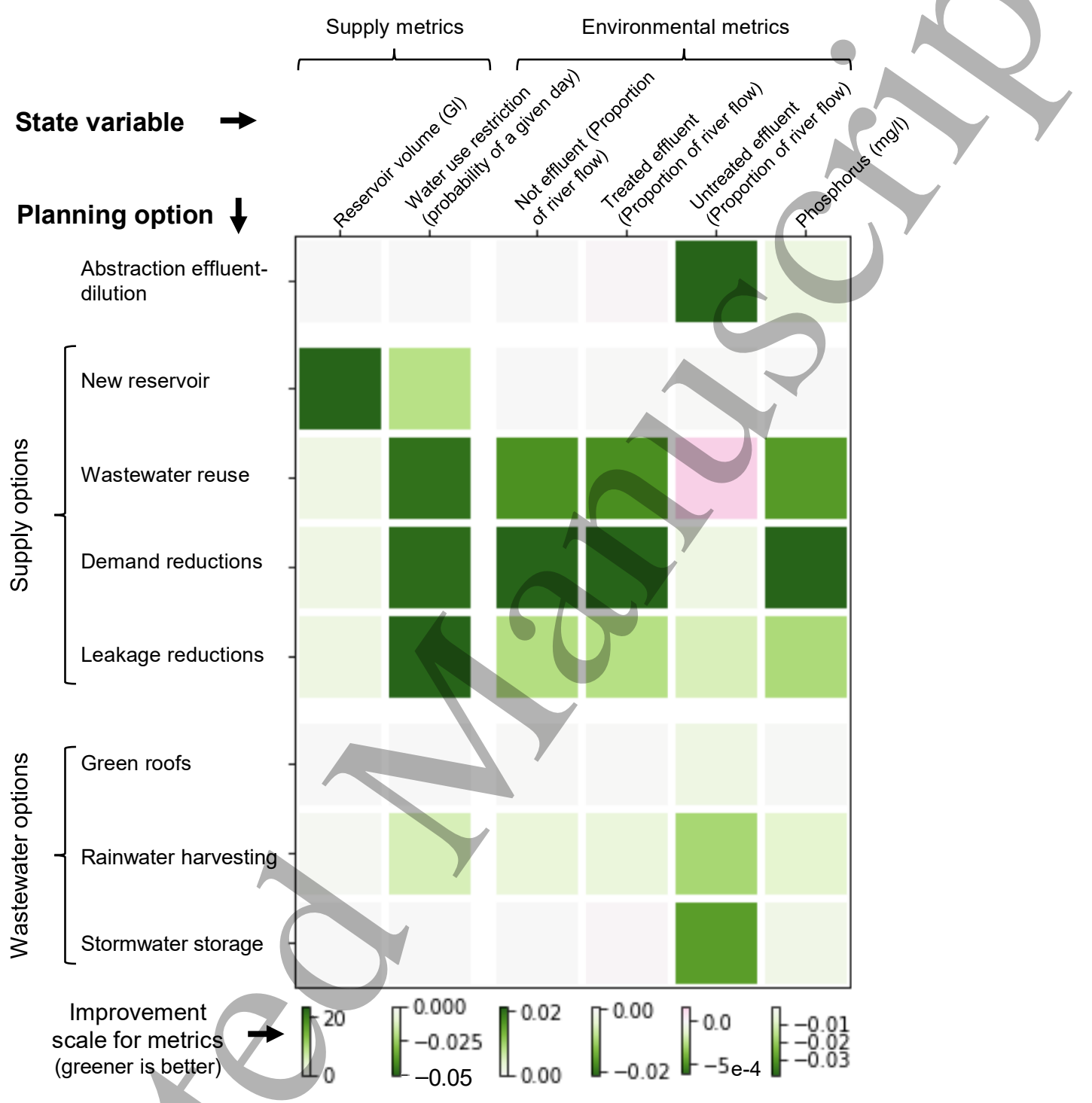

In context, we see that the abstraction effluent-dilution option (first row) of minimizing abstraction 320

Figure 9. Colour grid showing how different options compare to each other with respect to absolute change various state variables averaged over the entire timeseries, 1903-2018, (greener indicates a greater improvement while more pink indicates a decrease in performance). The change is the difference in a metric relative to the simulation without the option implemented (units given at top of column where option state variables are described).

321 Among the water supply options, we see improvement in all water supply metrics (first and second 322 columns), but also that they interact with water quality metrics. This interaction occurs through two 

mechanisms: changing the amount of water abstracted and changing the amount of treated effluent discharged. Each of wastewater reuse, demand reductions and leakage reductions interact with river quality via these mechanisms, but they do so differently.

Wastewater reuse (third row) improves quality metrics (except during spill events) by reducing treated effluent discharge and reducing the need for river abstraction. It does, however, also increase the concentration of untreated effluent during storm spill events (i.e. third row, fifth column is pink). This occurs because a portion of treated stormwater is being directed to the supply system rather than diluting the untreated storm spill effluent. We note that non-potable reuse (i.e. discharging into the river to enable greater abstractions) would have entirely negative impacts on water quality - since it is enabling greater abstractions without changing the amount of effluent.

Demand reductions (fourth row) improve downstream river quality outside of spill events in the same way - reducing household effluent and reducing river abstractions. Demand reductions do not change untreated effluent concentration since the amount of treated stormwater discharged during spill events is unchanged.

Leakage reductions (fifth row) reduce river abstractions but do not change treated effluent output. Therefore, their impact on raw water, treated effluent and phosphorus is not as strong as demand reduction or wastewater reuse (i.e. third, fourth and sixth columns in the fifth row are less green than in the third and fourth rows). However, leakage reductions do interact with spill events due to reduced abstractions and unchanged treated effluent output, diluting untreated effluent during spills (i.e. fifth column is light green).

A new reservoir simulated with historical water demand (second row) does not change abstractions or effluent discharge so does not interact with water quality downstream of the CityWat model domain.

Wastewater planning options have less impact on the wider urban water cycle - targeting primarily untreated effluent concentration.

The exception is rainwater harvesting, which impacts both supply and wastewater metrics (seventh row, green in all columns). If implemented at a city scale, it may reduce water use restrictions by supplying $90 \%$ of outdoor water demand not met by rainfall. However, this supply occurs disproportionately outside of drought conditions since harvesting tanks dry up during severe droughts, so the impact is not as significant as it might be. This repurposing of rainfall reduces river abstractions and treated effluent discharge so improves river quality outside of spill events. The impact on untreated effluent is smaller than we might expect, given the large storage capacity provided, since the storage is often full when storms that trigger spill events occur.

Green roofs (sixth row) reduce untreated effluent by reducing runoff from roofs that would go to sewers; however, this impact is relatively small compared to other options because the proposed area is small ( $2 \%$ of London's rooftop area, compared to $100 \%$ for rainwater harvesting, Table 1 ). Stormwater storage (eighth row) behaves as expected, reducing untreated effluent but without wider impacts beyond that. 
361 Our case for a wider systems view of the urban water cycle in planning and management was based on three hypotheses. The first was that abstracting and discharging into the same river while planning wastewater and supply separately will induce model errors in estimating downstream river quality. In our proof-of-concept analysis (Figure 7) we find this error to be significant. We believe this provides evidence that by explicitly accounting for the river state, we can identify unforeseen environmental risks. Abstraction licences for water suppliers are intended to safeguard UK rivers, however, as Figure 1 highlights, water quality on most rivers is not solely dependent on supply-side actions.

368 Meanwhile, proposed metrics for wastewater system performance in Water UK (2019), typically only 369 consider the time of year when discharges are made, not accounting for flows in their receiving waters nor the operation of the supply system. The results presented here provide evidence that the use of in-river water quality metrics are required to account for the environment in water planning.

372 The second hypothesis was that our proposed joint management option, abstraction effluent-dilution 373 (AED), could significantly reduce the concentration of spilled untreated effluent. Our results in Figures 3748 and 9 show that it achieves a performance comparable to infrastructure-based options, despite only 375 being a new channel for information in operations. In Figure 8 we see that it attains these gains 376 without reducing supply reliability, even though it occasionally limits abstraction. We also highlight that 377 a water company has complete control of this option, unlike some of the other analysed options (e.g. 378 demand reductions or rainwater harvesting). Thus, we argue that AED could be added to the water 379 companies' portfolio of future interventions, albeit with more nuanced design than the simple heuristic 380 presented here to account for factors such as flood risk management.

381 The final hypothesis was that planning options will impact state variables across the wider urban 382 water cycle. Figure 9 shows evidence of this. We see how supply-side options may improve river 383 quality by reducing abstractions. We also see that wastewater reuse may worsen the impact of 384 untreated effluent spills by redirecting stormwater that would be released as treated effluent (diluting 385 the spill) back into the supply system. Accounting for these systems level interactions in cost-benefit 386 analysis could have a significant impact on long-term planning decisions for water infrastructure.

\section{Future direction and concluding remarks}

388 This work demonstrates the case for integration and provides a proof-of-concept for achieving it. 389 However, we recognise that the presented top-down approach is not a panacea for water planning 390 and management, nor that the planning options assessment we perform should be taken as literal 391 recommendations for future investment. Although CityWat's model simulations have been compared 392 against historic reservoir volume and river samples of phosphorus (Figures 4, 5) showing good 393 agreement considering the model's simplicity, the field of integrated modelling research has yet to 394 converge on a suitable technique to reliably validate these types of models (Voinov \& Shugart, 2013; 395 Belete et al., 2017; Tscheikner-Gratl et al., 2019). Additionally, we use simplistic representations of 396 any individual modelled process in comparison to the state-of-the-art.

397 CityWat's lumped approach also assumes homogeneity in a heterogeneous system. This prevents 398 assessment of small-scale interventions, impacts of upstream water quality on abstractions and the 

role of options that improve system connectivity, such as the Thames Tideway Tunnel project (Loftus \& March, 2019). This project will link up London's storm spill overflows to its largest wastewater treatment works, and so cannot be represented by a city-scale lumped model.

402 In addition, our assessment is based on water management criteria only, and the approach should be extended to include wider benefits of multifunctional infrastructure such as green roofs (Ossa-Moreno et al., 2017; Hattab et al., 2020). Finally, the modelling approach is yet to be tested on how it could be used for flood risk management (Rezazadeh Helmi et al., 2019), planning under deep uncertainty (Erfani et al., 2018; Babovic \& Mijic, 2019) and examination of how different combinations of options might interact in a portfolio approach (Kasprzyk et al., 2012).

In a survey of water managers, Höllermann \& Evers (2017) found that model boundaries were the most commonly cited source of uncertainty. We hope that the scientific and wider communities interested in the sustainability of water systems will continue to build evidence for the importance of system boundaries on model simulations, and study how best to carry out integrated modelling to support the water industry in a future with fewer boundaries and one in which the environment is placed central to planning and management.

\section{Acknowledgements}

415 The research reported in this paper was taken as part of the CAMELLIA project (Community Water 416 Management for a Liveable London), funded by the Natural Environment Research Council (NERC) under grant NE/S003495/1. The models and data in this work are available at

418 http://dx.doi.org/10.5281/zenodo.3764678 and will continue to be updated at

419 https://github.com/barneydobson/citywat. The views expressed in this paper are those of the authors 420 alone, and not the organisations for which they work. The authors are grateful to Prof. Adrian Butler, 421 Prof. David Balmforth and two anonymous reviewers for comments on an earlier version of the manuscript that have improved the paper.

\section{References}

424 AECOM. (2017a). Spon's Architects' and Builders' Price Book. Abingdon: CRC Press.

425 AECOM. (2017b). Spon's Civil Engineering and Highway Works Price Book. Abingdon: CRC press.

Babovic, F., \& Mijic, A. (2019). The development of adaptation pathways for the long-term planning of urban drainage systems. Journal of Flood Risk Management, 12(March 2018), 1-12. https://doi.org/10.1111/jfr3.12538

Bach, P. M., Rauch, W., Mikkelsen, P. S., McCarthy, D. T., \& Deletic, A. (2014). A critical review of integrated urban water modelling - Urban drainage and beyond. Environmental Modelling and Software, 54, 88-107. https://doi.org/10.1016/j.envsoft.2013.12.018

Bailey, O., Arnot, T. C., Blokker, E. J. M., Kapelan, Z., Vreeburg, J., \& Hofman, J. A. M. H. (2019). Developing a stochastic sewer model to support sewer design under water conservation measures. Journal of Hydrology, 573(April), 908-917. https://doi.org/10.1016/j.jhydrol.2019.04.013

Behzadian, K., \& Kapelan, Z. (2015). Modelling metabolism based performance of an urban water system using WaterMet2. Resources, Conservation and Recycling, 99, 84-99. https://doi.org/10.1016/j.resconrec.2015.03.015

439 Belete, G. F., Voinov, A., \& Laniak, G. F. (2017). An overview of the model integration process: From 440 pre-integration assessment to testing. Environmental Modelling and Software, 87, 49-63. https://doi.org/10.1016/j.envsoft.2016.10.013 
442

443

444

445

446

447

448

449

450

451

452

453

454

455

456

457

458

459

460

461

462

463

464

465

466

467

468

469

470

471

472

473

474

475

476

477

478

479

480

481

482

483

484

485

486

487

488

489

490

491

492

493

494

495

Borgomeo, E., Mortazavi-Naeini, M., Hall, J. W., \& Guillod, B. P. (2018). Risk, Robustness and Water Resources Management under Uncertainty. Earth's Future, 6(3), 468-487. https://doi.org/10.1002/eft2.299

Burger, G., Bach, P. M., Urich, C., Leonhardt, G., Kleidorfer, M., \& Rauch, W. (2016). Designing and implementing a multi-core capable integrated urban drainage modelling Toolkit:Lessons from CityDrain3. Advances in Engineering Software, 100, 277-289.

https://doi.org/10.1016/j.advengsoft.2016.08.004

Centre for Ecology and Hydrology. (2020). National River Flow Archive. Retrieved March 11, 2020, from https://nrfa.ceh.ac.uk/

Cook, C., Gavin, H., Berry, P., Guillod, B., Lange, B., Rey Vicario, D., \& Whitehead, P. (2017). Drought planning in England: a primer. Oxford: Environmental Change Institute, University of Oxford, UK.

Coombes, P. J., \& Kuczera, G. (2002). Integrated urban water cycle management: Moving tówards systems understanding. Proceedings of the 2nd National Conference on Water Sensitive Urban Design, Engineers Australia, 1-8.

Coombes, P. J., Smit, M., \& MacDonald, G. (2016). Resolving boundary conditions in economic analysis of distributed solutions for water cycle management. Australian Journal of Water Resources, 20(1), 11-29. https://doi.org/10.1080/13241583.2016.1162762

Dobson, B., Wagener, T., \& Pianosi, F. (2019a). An argument-driven classification and comparison of reservoir operation optimization methods. Advances in Water Resources, 128(October 2018), 74-86. https://doi.org/10.1016/j.advwatres.2019.04.012

Dobson, B., Wagener, T., \& Pianosi, F. (2019b). How important are model structural and contextual uncertainties when estimating the optimized performance of water resource systems? Water Resources Research, (2017), 1-24. https://doi.org/10.1029/2018WR024249

Environment Agency. (2015). National Abstraction License Database. Retrieved from https://data.gov.uk/dataset/4484a9be-bfd1-4461-a8ff-95640bf6bc3d/national-abstraction-licensedatabase-returns

Environment Agency. (2019a). Catchment Abstraction Management Strategy (CAMS) Reference boundaries. Retrieved from https://data.gov.uk/dataset/e89f134c-f335-48e5-8d02a1d467ce6996/catchment-abstraction-management-strategy-cams-reference-boundaries

Environment Agency. (2019b). Revised Draft Water Resources Management Plan 2019 SupplyDemand Data at Company Level 2020/21 to 2044/45. Retrieved from https://data.gov.uk/dataset/fb38a40c-ebc1-4e6e-912c-bb47a76f6149/revised-draft-waterresources-management-plan-2019-supply-demand-data-at-company-level-2020-21-to-204445\#licence-info

Environment Agency. (2020). Open water quality archive datasets (WIMS). Retrieved March 19, 2020, from https://environment.data.gov.uk/water-quality/view/download

Erfani, T., Pachos, K., \& Harou, J. J. (2018). Real-Options Water Supply Planning: Multistage Scenario Trees for Adaptive and Flexible Capacity Expansion Under Probabilistic Climate Change Uncertainty. Water Resources Research, 54(7), 5069-5087. https://doi.org/10.1029/2017WR021803

European Commission. (2016). Urban Wastewater Treatment Directive - Treatment Plants. Retrieved March 17, 2020, from https://uwwtd.eu/United-Kingdom/download

Gleick, P. H. (2003). Global Freshwater Resources: Soft-Path Solutions for the 21st Century. Science, 302(5650), 1524-1528. https://doi.org/10.1126/science.1089967

Gooddy, D. C., Ascott, M. J., Lapworth, D. J., Ward, R. S., Jarvie, H. P., Bowes, M. J., ... Surridge, B. W. (2017). Mains water leakage: Implications for phosphorus source apportionment and policy responses in catchments. Science of the Total Environment, 579, 702-708. https://doi.org/10.1016/j.scitotenv.2016.11.038

Hamilton, A. (2013). Public communication on Thames Tideway. Retrieved from https://infrastructure.planninginspectorate.gov.uk/document/2040941

Hattab, M. H. El, Theodoropoulos, G., Rong, X., \& Mijic, A. (2020). Applying the Systems Approach to Decompose the SuDS Decision-Making Process for Appropriate Hydrologic Model Selection.

Höllermann, B., \& Evers, M. (2017). Perception and handling of uncertainties in water management- 
A study of practitioners' and scientists' perspectives on uncertainty in their daily decisionmaking. Environmental Science \& Policy, 71, 9-18. https://doi.org/10.1016/j.envsci.2017.02.003 of gridded climate observations. Geoscience Data Journal, 6(2), 151-159. https://doi.org/10.1002/gdj3.78

Jarvie, H. P., Neal, C., \& Withers, P. J. A. (2006). Sewage-effluent phosphorus: A greater risk to river eutrophication than agricultural phosphorus? Science of the Total Environment, 360(1-3), 246253. https://doi.org/10.1016/j.scitotenv.2005.08.038

Kasprzyk, J. R., Reed, P. M., Characklis, G. W., \& Kirsch, B. R. (2012). Many-objective de Novo water supply portfolio planning under deep uncertainty. Environmental Modelling and Software, 34, 87-104. https://doi.org/10.1016/j.envsoft.2011.04.003

Kasprzyk, J. R., Smith, R. M., Stillwell, A. S., Madani, K., Ford, D., McKinney, D., \& Sorooshian, S. (2018). Defining the role of water resources systems analysis in a changing future. Journal of Water Resources Planning and Management, 144(12), 1-3. https://doi.org/10.1061/(ASCE)WR.1943-5452.0001010

Kuczera, G. (1992). Water supply headworks simulation using network linear programming. Advances in Engineering Software, 14(1), 55-60. https://doi.org/10.1016/0965-9978(92)90084-S

Loftus, A., \& March, H. (2019). Integrating what and for whom? Financialisation and the Thames Tideway Tunnel. Urban Studies, 56(11), 2280-2296. https://doi.org/10.1177/0042098017736713

Loucks, D. P. (2000). Sustainable water resources management. Water International, 25(1), 3-10. https://doi.org/10.1080/02508060008686793

Mitchell, V. G. (2006). Applying integrated urban water management concepts: A review of Australian experience. Environmental Management, 37(5), 589-605. https://doi.org/10.1007/s00267-0040252-1

Mitchell, V. G., Mein, R. G., \& McMahon, T. A. (2001). Modelling the urban water cycle. Environmental Modelling and Software, 16(7), 615-629. https://doi.org/10.1016/S1364-8152(01)00029-9

Mortazavi-Naeini, M., Bussi, G., Elliott, J. A., Hall, J. W., \& Whitehead, P. G. (2019). Assessment of risks to public water supply from low flows and harmful water quality in a changing climate. Water Resources Research, 2018WR022865. https://doi.org/10.1029/2018WR022865

NERA. (2019). Assessing Ofwat's Funding and Incentive Targets for Leakage Reduction. (March).

Olsson, G., Carlsson, B., Comas, J., Copp, J., Gernaey, K. V., Ingildsen, P., ... Åmand, L. (2014). Instrumentation, control and automation in wastewater - From London 1973 to Narbonne 2013. Water Science and Technology, 69(7), 1373-1385. https://doi.org/10.2166/wst.2014.057

Ordnance Survey. (2019). OS Open Rivers. Retrieved March 17, 2020, from https://www.ordnancesurvey.co.uk/business-government/products/open-map-rivers

Ossa-Moreno, J., Smith, K. M., \& Mijic, A. (2017). Economic analysis of wider benefits to facilitate SuDS uptake in London, UK. Sustainable Cities and Society, 28, 411-419. https://doi.org/10.1016/j.scs.2016.10.002

Paredes-Arquiola, J., Solera, A., Martinez-Capel, F., Momblanch, A., \& Andreu, J. (2014). Integrating water management, habitat modelling and water quality at the basin scale and environmental flow assessment: case study of the Tormes River, Spain. Hydrological Sciences Journal, 59(34), 878-889. https://doi.org/10.1080/02626667.2013.821573

Quinn, J. D., Reed, P. M., Giuliani, M., \& Castelletti, A. (2017). Rival framings: A framework for discovering how problem formulation uncertainties shape risk management trade-offs in water resources systems. Water Resources Research, 53(8), 7208-7233. https://doi.org/10.1002/2017WR020524

Rahaman, M. M., \& Varis, O. (2005). Integrated water resources management: evolution, prospects and future challenges. Sustainability: Science, Practice and Policy, 1(1), 15-21. https://doi.org/10.1080/15487733.2005.11907961

Rezazadeh Helmi, N., Verbeiren, B., Mijic, A., van Griensven, A., \& Bauwens, W. (2019). Developing a modeling tool to allocate Low Impact Development practices in a cost-optimized method. Journal of Hydrology, 573(March), 98-108. https://doi.org/10.1016/j.jhydrol.2019.03.017 Modelling and Software, 41, 139-150. https://doi.org/10.1016/j.envsoft.2012.11.015 
Salvadore, E., Bronders, J., \& Batelaan, O. (2015). Hydrological modelling of urbanized catchments: A review and future directions. Journal of Hydrology, 529(P1), 62-81. https://doi.org/10.1016/j.jhydrol.2015.06.028

Tscheikner-Gratl, F., Bellos, V., Schellart, A., Moreno-Rodenas, A., Muthusamy, M., Langeveld, J., ... Tait, S. (2019). Recent insights on uncertainties present in integrated catchment water quality modelling. Water Research, 150, 368-379. https://doi.org/10.1016/j.watres.2018.11.079

Vogel, R. M., Lall, U., Cai, X., Rajagopalan, B., Weiskel, P. K., Hooper, R. P., \& Matalas, N. C. (2015). Hydrology: The interdisciplinary science of water. Water Resources Research, 51(6), 44094430. https://doi.org/10.1002/2015WR017049

Voinov, A., \& Shugart, H. H. (2013). "Integronsters", integral and integrated modeling. Environmental Modelling and Software, 39, 149-158. https://doi.org/10.1016/j.envsoft.2012.05.014

Vörösmarty, C. J., McIntyre, P. B., Gessner, M. O., Dudgeon, D., Prusevich, A., Green, P., ... Davies, P. M. (2010). Global threats to human water security and river biodiversity Nature, 467(7315), 555-561. https://doi.org/10.1038/nature09440

Water UK. (2019). A framework for the production of Drainage and Wastewater Management Plans. Retrieved from https://www.water.org.uk/wpcontent/uploads/2020/01/Water_UK_DWMP_Framework_Report_Main_September-2019.pdf

Zhao, W., Beach, T. H., \& Rezgui, Y. (2016). Optimization of Potable Water Distribution and Wastewater Collection Networks: A Systematic Review and Future Research Directions. IEEE Transactions on Systems, Man, and Cybernetics: Systems, 46(5), 659-681. https://doi.org/10.1109/TSMC.2015.2461188 